\title{
A voltammetric epithelial sodium channels immunosensor using screen-printed carbon electrode modified with reduced graphene oxide
}

\author{
Yeni Wahyuni Hartatia ${ }^{a *}$, Sonya Fatimah Yusup ${ }^{a}$, Fitrilawatib ${ }^{\mathrm{b}}$, Santhy Wyantuti ${ }^{\mathrm{a}}$, Yulia Sofiatin ${ }^{\mathrm{c}}$ and \\ Shabarni Gaffara
}

${ }^{a}$ Department of Chemistry, Faculty of Mathematics and Natural Sciences, Universitas Padjadjaran Bandung, Indonesia

${ }^{b}$ Department of Physics, Faculty of Mathematics and Natural Sciences, Universitas Padjadjaran Bandung, Indonesia

${ }^{c}$ Department of Public Health, Faculty of Medicine, Universitas Padjadjaran Bandung, Indonesia

\begin{tabular}{l} 
C H R O N I C L E \\
\hline Article history: \\
Received October 8,2019 \\
Received in revised form \\
November 21,2019 \\
Accepted February 18,2020 \\
Available online \\
February 18,2020 \\
Keywords: \\
Epithelial sodium channels \\
(ENaC) \\
Anti-ENaC \\
Hypertension \\
Electrochemical \\
immunosensor \\
Reduced graphene oxide
\end{tabular}

\section{A B S T R A C T}

Epithelial sodium channels $(\mathrm{ENaC})$ is a protein that plays a role in maintaining sodium levels and can be used as a biomarker of hypertension. This study aims to develop an electrochemical immunosensor for detecting $\mathrm{ENaC}$ using a screen-printed carbon electrode (SPCE), which was modified with reduced graphene oxide (RGO). The RGO improves the performance of immunosensor because it contains - $\mathrm{COOH}$ groups that can form a covalent bond with the terminal $-\mathrm{NH}_{2}$ of anti-ENaC. The result shows that the optimum concentration of anti-ENaC was $1.0 \mu \mathrm{g} / \mathrm{mL}$ for $30 \mathrm{~min}$ incubation time. The various concentration of $\mathrm{ENaC}$ has a linear relationship with the decreasing of ferricyanide peak current signal with the range of 0.01-1.5 $\mathrm{ng} / \mathrm{mL}$, and the limit of detection was $0.198 \mathrm{ng} / \mathrm{mL}$. The level of ENaC concentration in urine samples can be used for the realization of a point-of-care device for early detection of hypertension.

\section{Introduction}

Hypertension is a significant risk factor for heart attack, stroke, and kidney failure. One of the markedly of hypertension is known because of a high salt intake especially, sodium salt in the blood that can elevate blood pressure in hypertensive patients ${ }^{1,2}$. Physiological studies show that kidneys play an essential role in maintaining sodium balance, extracellular fluid volume, and long-term blood pressure control. Most of the sodium is absorbed to achieve the appropriate level of sodium excretion in the urine ${ }^{3}$. An epithelial sodium channels $(\mathrm{ENaC})$ protein, which acts as a sodium transporter in the kidney is responsible for limiting the reabsorption of sodium in the distal nephron and extracellular fluid balance 4 . ENaC is a transmembrane protein that is located mostly in the epithelium. As a constitutively active channel, $\mathrm{ENaC}$ allows the flow of $\mathrm{Na}^{+}$ions from the lumen into epithelial cells,

* Corresponding author.

E-mail address: yeni.w.hartati@unpad.ac.id (Y.Wahyuni Hartati)

(C) 2020 Growing Science Ltd. All rights reserved.

doi: $10.5267 /$ j.ccl.2020.2.001 
across the apical cell membrane. The absorbed $\mathrm{Na}+$ ion is then pumped out of the cell into the interstitial fluid by the action of $\mathrm{Na}^{+} / \mathrm{K}^{+}$ATPase located on the basolateral membrane. ENaC modulates the amount of $\mathrm{Na}^{+}$in extracellular fluid, and it plays an essential role in regulating the extracellular fluid volume and blood pressure ${ }^{5}$. $\mathrm{ENaC}$ levels can measure from various specific locations, one of which is a kidney. The kidneys are a good source of sodium excretion related to hypertension. Urine is the closest source of the kidney. Therefore the $\mathrm{ENaC}$ levels can be determined in the urine ${ }^{6}$.

Sofiatin \& Roesli, 2018 was measured the $\mathrm{ENaC}$ concentration in various urine samples of three group patients: non-hypertension, hypertension with and without a history, by using ELISA methods. The $\mathrm{ENaC}$ protein was detected in the supernatant and the pellet of the urine after centrifugation. The results showed that $\mathrm{ENaC}$ protein levels in non-hypertension patients were $1.12 \mathrm{ng} / \mathrm{mL}$, hypertension with history patients were $2.7 \mathrm{ng} / \mathrm{mL}$, and hypertension without history patients were $4.0 \mathrm{ng} / \mathrm{mL}^{6}$. This result indicated that $\mathrm{ENaC}$ concentration in the urine sample might be related to hypertension. However, the ELISA method has several disadvantages, which are a time-consuming and expensive instrument and reagent ${ }^{7,8}$.

An electrochemical immunosensor is an alternative method to detect and measure the ENaC levels. Electrochemical immunosensor is an analytical tool, which combines the specific interactions of antibody or antibody fragments as element recognition against a particular antigen based on electrochemical transduction. Immunosensors have known as a combination of immunochemistry and sensor chemistry that detect the interaction of an antibody with an antigen with high selectivity and sensitivity which is popularly used in the field of clinical diagnoses. The advantages of electrochemical immunosensors are low detection limits, small volumes, simple instrumentation, and miniature systems that can be easily made and integrated into biochips ${ }^{9,10,11}$.

The screen-printed working electrode in the electro-analysis is most widely used because of the low cost, small, high sensitivity, and the surfaces are easy to modify with other molecules such as proteins or nanomaterials that can increase the active area and electrocatalytic properties ${ }^{12}$. Many screens printed electrodes are modified with nanomaterials such as graphene oxide, cerium dioxide, and nanogold to improve the electrochemical performance. Modification of SPCE with graphene oxide can improve electrochemical performance ${ }^{13}$. Graphene oxide is a derivative compound of graphene, which contain not only carbon but also oxygenic residue that has attracted characteristics. It's become researches interest because of its potential in increasing the conductivity of sensors and providing an attachment area for various biomolecules, such as proteins, enzymes, and nucleic acids. Graphene oxide has applied in many applications in the electrochemical biosensor field. The graphene oxidebased electrochemical sensor was developed for detecting various kinds of analytes, such as dyes synthesized sunset yellow and tartrazine ${ }^{14}$, glucose ${ }^{15}$, uric acid, ascorbic acid, and dopamine ${ }^{16}$, fat test ${ }^{17}$, organophosphate parathion pesticides ${ }^{18}$, CRP proteins ${ }^{7}$, and cortisol and lactate ${ }^{8}$.

This work reported the modification of screen-printed carbon electrodes (SPCE) using graphene oxide and used as an immunosensor for the detection of ENaC. We examined the immunosensor proposed for the determination of $\mathrm{ENaC}$ in the urine sample. The optimum experimental conditions that affect immunosensor performance also were studied.

\section{Results and Discussion}

\subsection{Oxide Graphene Reduction and Modification of Electrodes}

The GO must be sonicated before used as an electrode modifier. The sonication process is required for the physical exfoliation of GO sheets and to reduce the Van der Waals forces that exist between the layers of the 2D GO sheet if it stored for long period ${ }^{8}$. The electrochemical response of the SPCE before 
and after modified with RGO was observed using cyclic voltammetry of $10 \mathrm{mM} \mathrm{K}_{3}\left[\mathrm{Fe}(\mathrm{CN})_{6}\right]$ containing $0.1 \mathrm{M} \mathrm{KCl}$, as shown in Fig. $1 \mathrm{~A}$.

A.

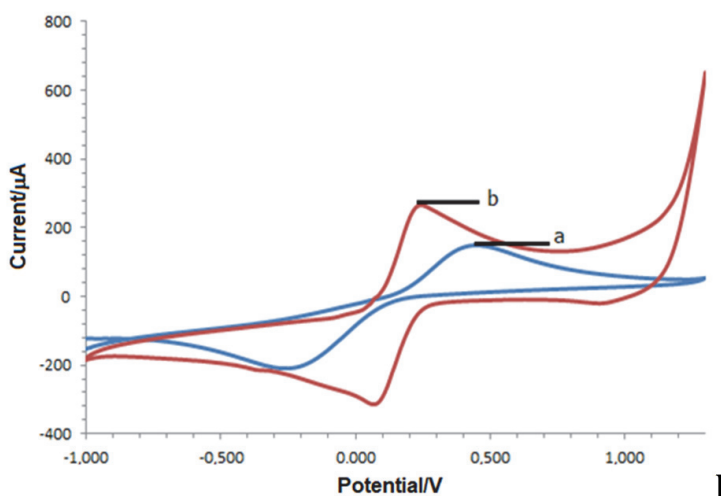

B.

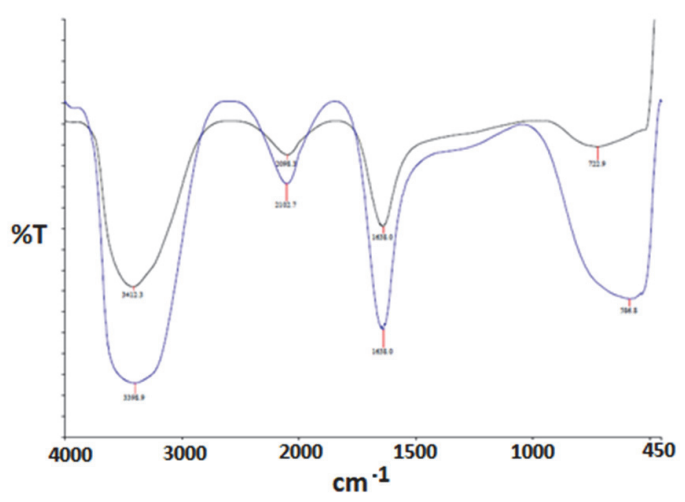

Fig. 1 A. Electrochemical characterization of $\left[\mathrm{Fe}(\mathrm{CN})_{6}\right]^{3-4-}$ using cyclic voltammetry with the potential range -1.0 to $1.3 \mathrm{~V}$, scan rate $100 \mathrm{mV} / \mathrm{s}$ (a) SPCE, and (b) SPCE/RGO. B. FTIR spectrum of GO and RGO.

Fig. 1A shows that the current response of $\left[\mathrm{Fe}(\mathrm{CN})_{6}\right]^{3-/ 4-}$ on the SPCE-RGO surface increases five times higher than the SPCE before modification. This enhancement is because of the characteristics of RGO, due to reduced oxygenic groups causes higher conductivity. Also, the electrostatic repulsion between negatively charged species $\left[\mathrm{Fe}(\mathrm{CN})_{6}\right]^{3-/ 4-}$ and oxygenic groups of RGO cause better electron transfer. The reduction of GO into RGO was characterized by using the FTIR method. Fig. 1 B depicts the FTIR spectrum of GO and RGO. The O-H absorption appeared at a wavelength of $3398.9 \mathrm{~cm}^{-1}$. Then there was also an absorption band at a wavelength of $1638 \mathrm{~cm}^{-1}$ which was assumed as a stretch of $\mathrm{C}=\mathrm{O}$ of the carboxylic group. The peak intensity of all bands in the RGO was reduced compared to GO due to the reduced oxygenic group electrochemically.

\subsection{Immobilization of Anti-ENaC onto SPCE-RGO}

In this study, two immobilization methods were carried out; they are passive adsorption and covalent bond formation. The passive adsorption method was based on the electrostatic interaction and other physical interaction between anti-ENaC with SPCE. Whereas, the covalent bond formation method was done by using CMD and RGO to increase the sensitivity of the working electrode. According to Fig. 2, the passive adsorption of anti $\mathrm{ENaC}$ to the SPCE produces a decrease of current response of $\Delta \mathrm{I}=$ $3.754 \mu \mathrm{A}$, while, in the covalent bond formation method, the $\Delta \mathrm{I}=6.516 \mu \mathrm{A}$, and the RGO-anti-ENaC has a significant decrease that was $17.9749 \mu \mathrm{A}$. The decrease of current response occurs because the covalent bond formation introduced more anti-ENaC to the electrode surface. The passive adsorption produced less effective immobilization of anti-ENaC due to inconsistent orientation. When the anti$\mathrm{ENaC}$ was passively absorbed to the electrode surfaces, the anti-ENaC was stabilized and weakly binds to the electrode surface via electrostatic and other physical interaction resulting in random paratope orientation and perhaps result in significant loss of antibody activity ${ }^{17}$. Whereas, the covalent bond formation of anti-ENaC with $\mathrm{CMD}$ was not as good as using RGO because the availability anti-ENaC binding site was not too much due to the incubation time of CMD to the electrode surface. Therefore, the covalent bond formation using RGO was used because it facilitated the anti-ENaC attachment well enough to produce a significant current reduction response.

When anti-ENaC was immobilized on the surface of a conductive electrode, there is an increase in resistance of current of $\left[\mathrm{Fe}(\mathrm{CN})_{6}\right]^{3-/ 4-}$. Since the protein structure demonstrates the isolated behavior of non-conductor biomolecules, the transfer of electrons from the mediator $\left[\mathrm{Fe}(\mathrm{CN})_{6}\right]^{3-4-}$ were blocked 
and the electrochemical signal decreases. The - $\mathrm{COOH}$ group present in RGO can be conjugated with anti-ENaC covalently via an amide coupling. The carboxyl group was activated using EDC and NHS because the carboxyl group is highly reactive to the carbodiimide group on EDC and forms the oasylorourea intermediates. Then when reacting with NHS, a succinimide ester that more stable intermediate was formed ${ }^{10,11,21}$ and highly reactive to the terminal amine group of anti-ENaC. By dropping the anti-ENaC on SPCE-RGO forms a stable amide bond between the amine group of anti$\mathrm{ENaC}$ and the carboxyl group of RGO, as illustrated in Fig. 3.

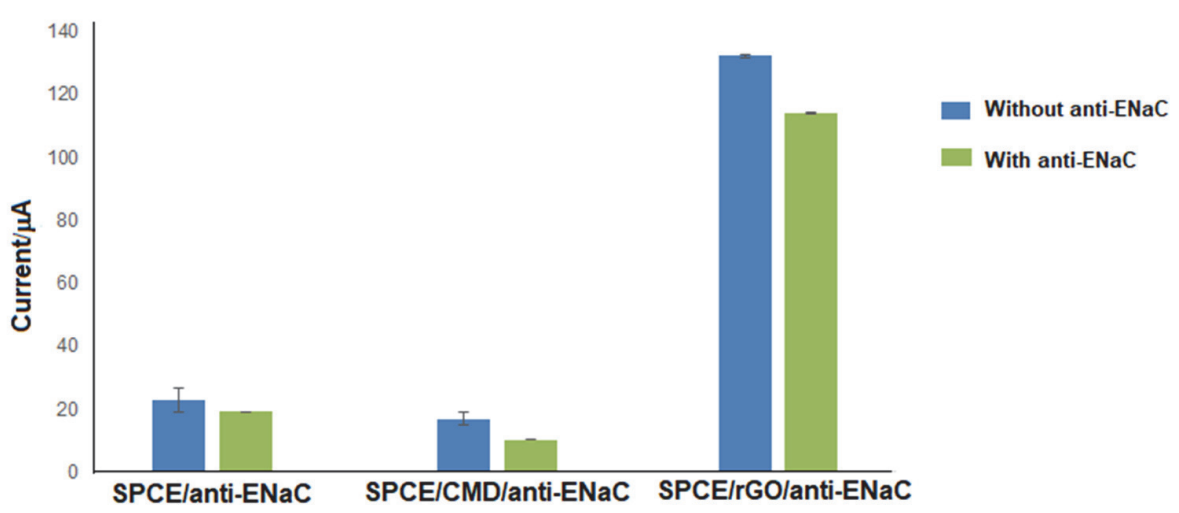

Fig. 2. The comparison of two immobilization methods of anti-ENaC onto SPCE-RGO; via passive adsorption and covalent bond formation.
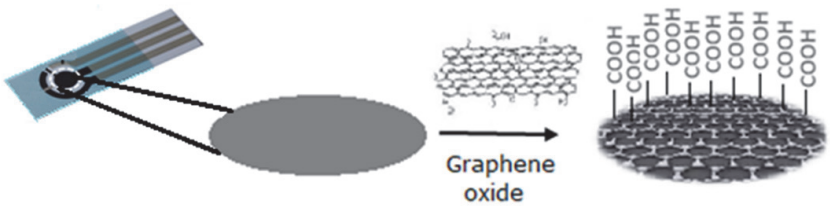

Electrochemically reduced from $0.1 \mathrm{~V}$ to $-2.5 \mathrm{~V}$
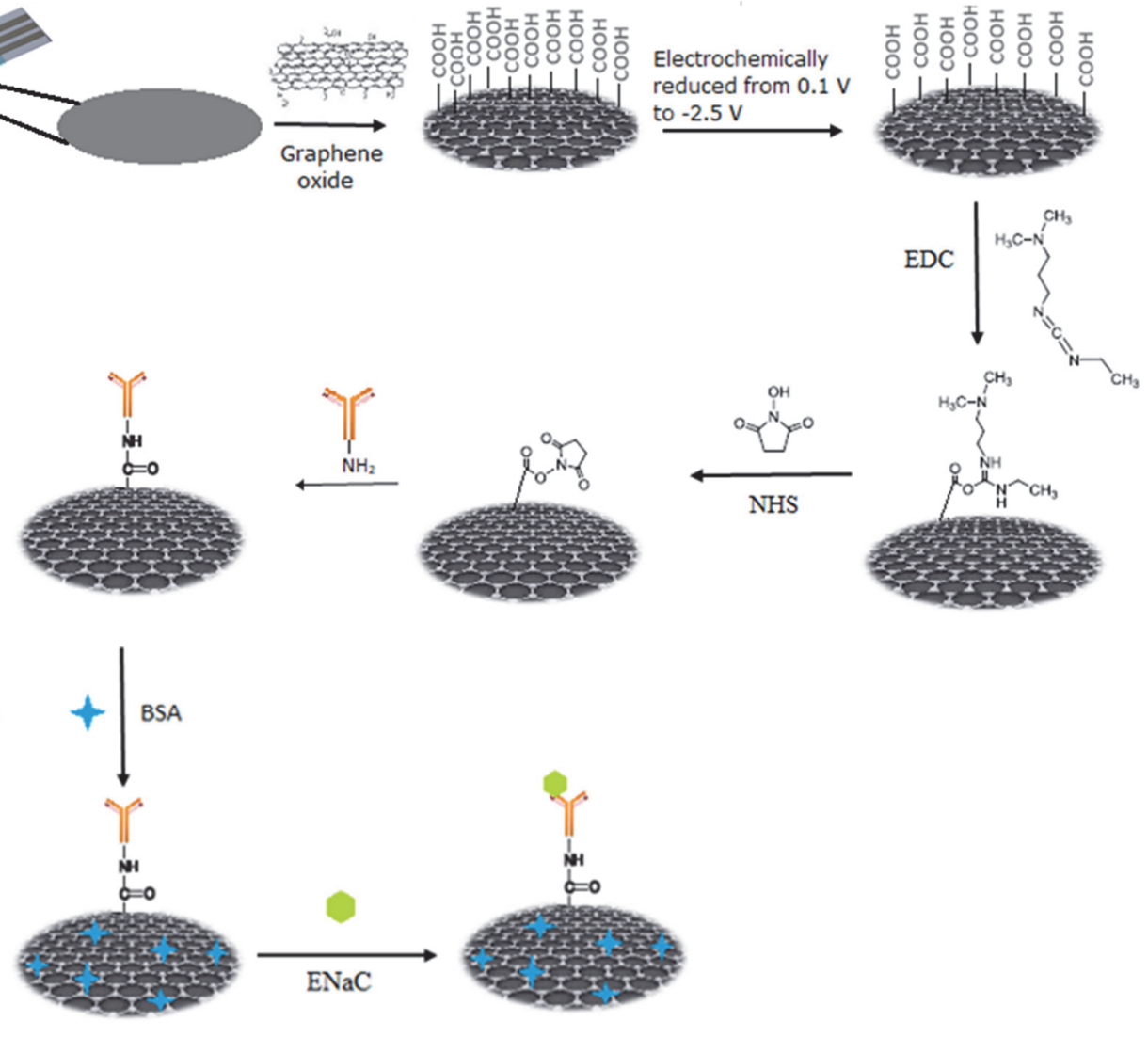

Fig. 3. Scheme of immunosensor for the detection of $\mathrm{ENaC}$ 
Fig. 4 A shows the Nyquist plot of the impedance resistance value. In contrast to the current value, the resistance value of the electrode was decreased significantly after being modified with RGO. Furthermore, after anti-ENaC immobilization, there was an increase in resistance because the electron transfer during a redox reaction was difficult to penetrate the protein layer on the surface of the conductive electrode. These results indicate that anti-ENaC has been successfully immobilized to the electrode ${ }^{17}$.

Immunoreaction that occurred between $\mathrm{ENaC}$ and anti-ENaC was characterized using cyclic voltammetry of the $\left[\mathrm{Fe}(\mathrm{CN})_{6}\right]^{3-/ 4-}$. Fig. 4 B shows that the decrease in peak current response occurred after the addition of $\mathrm{ENaC}$. The presence of $\mathrm{ENaC}$ protein on the surface of the electrode caused the $\left[\mathrm{Fe}(\mathrm{CN})_{6}\right]^{3-/ 4-}$ species became farther away from the electrode surface. Therefore, the process of electron transfer during the redox reaction was inhibited.

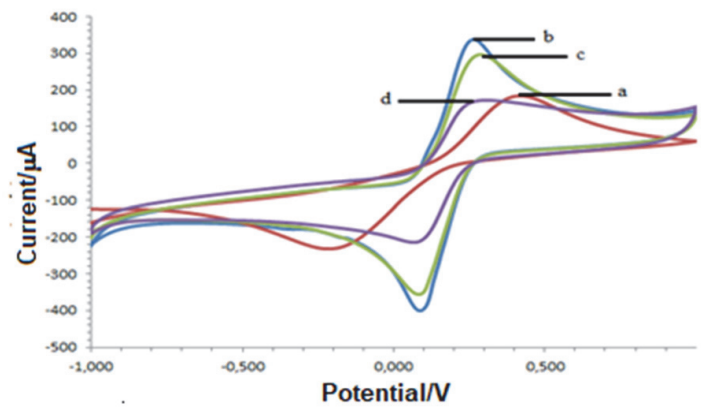

A.

Fig. 4. A.Cyclic voltammograms, and B. SPCE/RGO/anti-ENaC. Inset: zoomed spectrum.

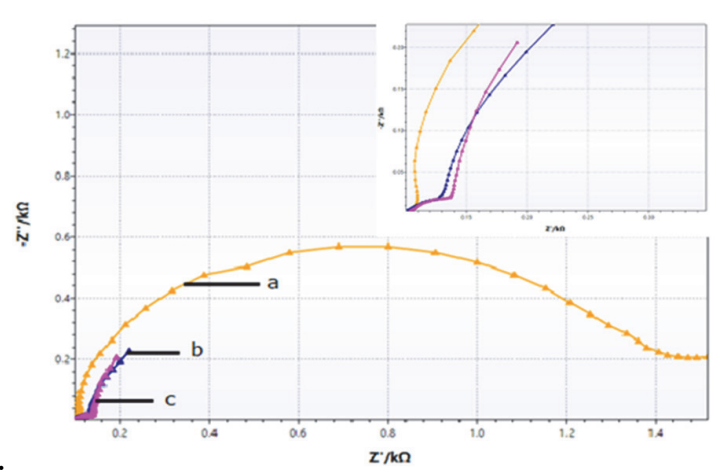

B.

yquist plot of (a) SPCE. (b) SPCE/RGO. (c)
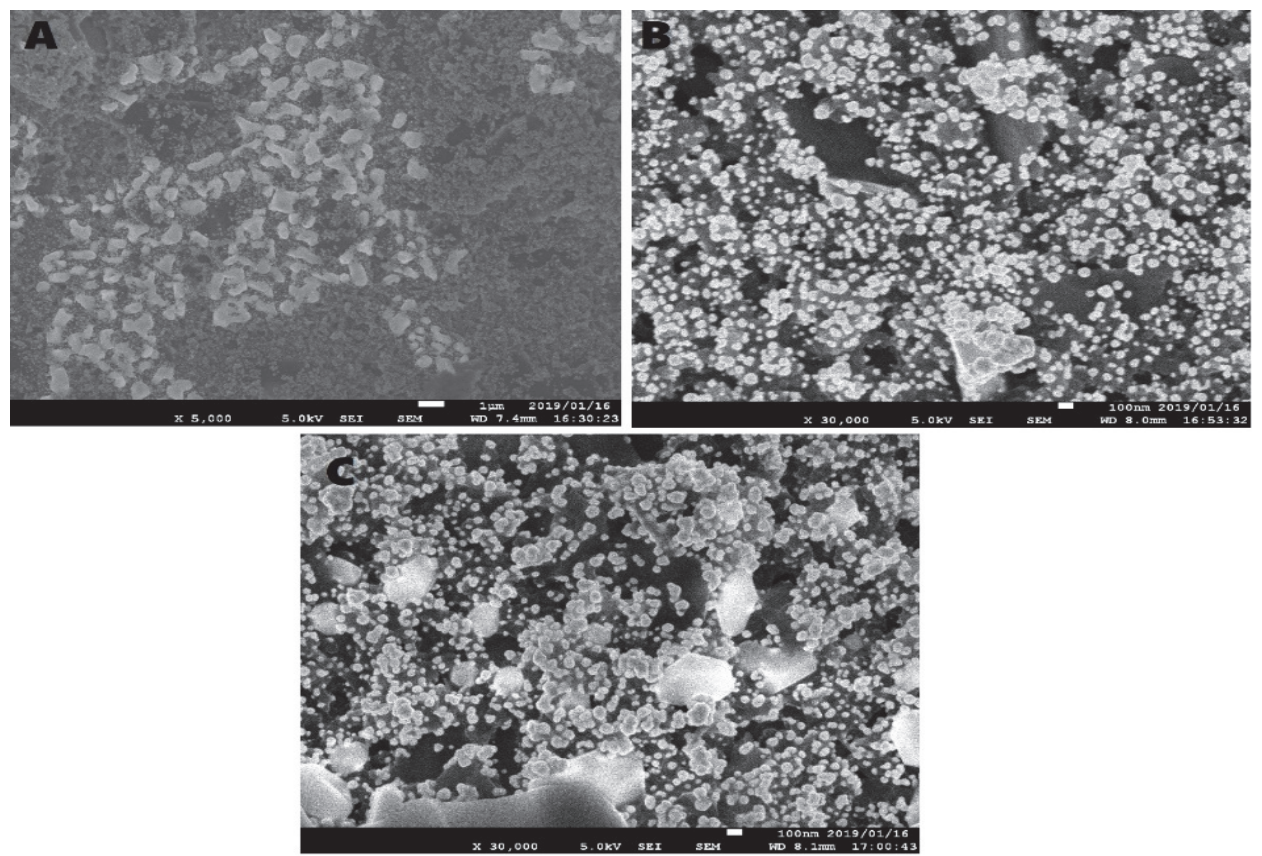

Fig. 5. SEM surface images of (A) SPCE, (B) SPCE/RGO, and (C) SPCE/RGO/Anti-ENaC. The magnificent was $\times 5,000$ and $\times 30,000$.

SEM characterization was carried out to determine the morphology of the SPCE before and after modified with RGO. Fig. 5 A shows a smoother and more uniform SPCE surface before modification. 
Fig. $5 \mathrm{~B}$ shows a coarser structure of SPCE-RGO so that it can provide an active surface area for the immobilization of anti-ENaC. Fig. $5 \mathbf{C}$ reveals that a particulate appears with several aggregates above the surface of the $\mathrm{RGO}$, indicating that anti-ENaC was successfully immobilized.

\subsection{Optimization of Analytical Parameter}

The analytical parameters were tested using a redox system of $\left[\mathrm{Fe}(\mathrm{CN})_{6}\right]^{3-/ 4-}$. The measurements were conducted by differential pulse voltammetry technique with the potential range -1.0 to $1.0 \mathrm{~V}$ and a scanning rate of $0.008 \mathrm{~V} / \mathrm{s}$. Optimizations of the immunosensor were done by using various concentration of anti-ENaC $(0.1 ; 0.5 ; 1 ; 2$, and $10 \mu \mathrm{g} / \mathrm{mL})$ and variation of incubation times $(10,30$, 60, and 90 minutes).

Fig. 6A shows that the optimum concentration of anti-ENaC was $1 \mu \mathrm{g} / \mathrm{mL}$ because it produces the lowest current response. As the anti-ENaC concentration increases, there is a decrease in electron flow, which indicates that the anti-ENaC immobilized is well oriented. The anti-ENaC provides a considerable active site for the immunoreaction with the ENaC. However, the current response increased when the anti-ENaC concentration was higher than $1 \mu \mathrm{g} / \mathrm{mL}$ because of the high background current response. Also, the high anti-ENaC density causes a non-uniform orientation so that anti-ENaC loses antibody recognition activity, which might be due to the part of anti-ENaC attached to the electrode was the active site, which should be bind to the antigen.
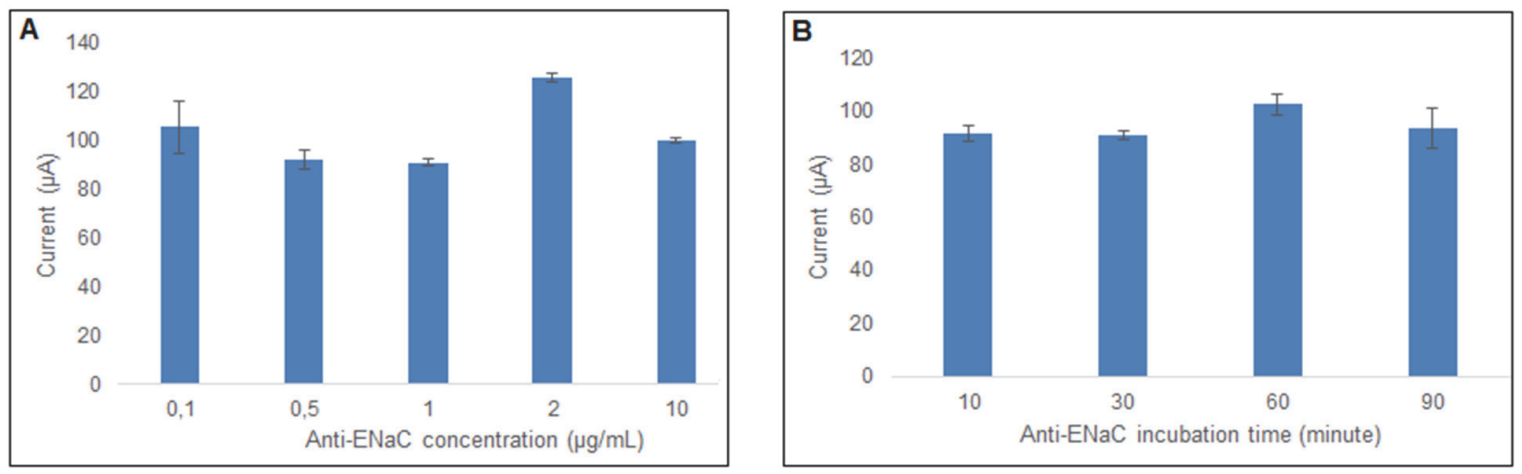

Fig. 6 A. The optimization of anti-ENaC concentration, and $\mathbf{B}$. The optimization anti-ENaC incubation time by using a differential pulse of $\left[\mathrm{Fe}(\mathrm{CN})_{6}\right]^{3-/ 4-}$ containing $0.1 \mathrm{M} \mathrm{KCl}$.

The optimum incubation time of anti-ENaC onto the electrode was $30 \mathrm{~min}$, as shown in Fig. 6 B. The attachment of anti-ENaC on the electrode surface, inhibit the ferricyanide redox process, caused the reduction of peak currents. While the current response increased at 60 and 90 minutes, this might be caused by, the electrode surface was saturated with anti-ENaC and produced a high electrochemical signal.

\subsection{The Calibration Curve}

A calibration curve was made to determine the performance of the analytic parameters of the immunosensor. Immunosensors were tested against various concentration of $\mathrm{ENaC} ;(0 ; 0.009375$; $0.09375 ; 0.1875 ; 0.375 ; 0.75 ; 1$; and $1.5 \mathrm{ng} / \mathrm{mL})$. Fig. 7 A shows the decrease of peak current with an increasing concentration of $\mathrm{ENaC}$. The attachment of $\mathrm{ENaC}$ creates a barrier to the electron transfer process of the working electrode, which ultimately lowers the peak current. The linear relationship of the immunosensor response to various $\mathrm{ENaC}$ concentration was plotted into a calibration curve, as seen in Fig. 7 B. 

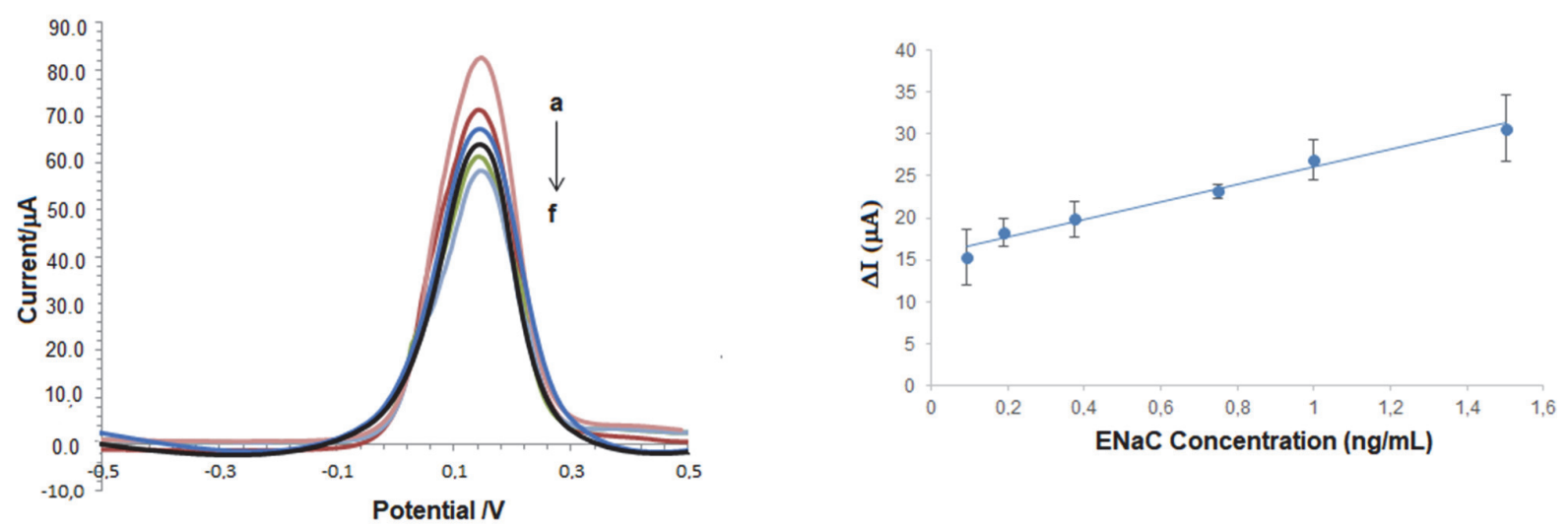

Fig. 7 A. Electrochemical response of the immunosensor at various concentration of $\mathrm{ENaC}$; (a) 0,09375 $\mathrm{ng} / \mathrm{mL}$. (b) $0,1875 \mathrm{ng} / \mathrm{mL}$. (c) $0,375 \mathrm{ng} / \mathrm{mL}$ (d) $0,75 \mathrm{ng} / \mathrm{mL}$. (e) $1 \mathrm{ng} / \mathrm{mL}$. (f) $1,5 \mathrm{ng} / \mathrm{mL}$. B. Calibration curve of the immunosensor for the detection of $\mathrm{ENaC}$ protein. Each concentration triplicate measured its electrochemical response using a differential pulse voltammetry technique in the potential range 1.0 to $1.0 \mathrm{~V}$ with a scanning rate of $0.008 \mathrm{~V} / \mathrm{s}$ using a redox system of using differential pulse of $\left[\mathrm{Fe}(\mathrm{CN})_{6}\right]^{3-/ 4-}$ containing $0.1 \mathrm{M} \mathrm{KCl}$.

According to Fig. $7 \mathbf{B}$, the linearity of calibration curve obtained in the concentration range of $0.09375-1.5 \mathrm{ng} / \mathrm{mL}$ with the equation $\Delta \mathrm{I}=10.485[\mathrm{ENaC}]+15.56$ and $\mathrm{R} 2=0.9789$. Limit of detection (LoD) was determined using the equation $[\mathrm{ENaC}]=\left(Y_{b}+3 S_{b}\right) / \mathrm{b}, Y_{b}$ was the intercept of the calibration curve, $S_{b}$ was the $S_{X / Y}$ which estimates the random errors in the y-direction, and b was the slope ${ }^{18}$. LoD was $0.198 \mathrm{ng} / \mathrm{mL}$, and the limit of quantification was $0.599 \mathrm{ng} / \mathrm{mL}$.

\subsection{The Analysis of Urine Samples}

The proposed immunosensor was tested on urine samples containing ENaC protein. The procedure was the same as determining the response of standard $\mathrm{ENaC}$. The result shows that the fresh urine sample has an $\mathrm{ENaC}$ concentration of $0.5967 \pm 0.014$, compared to the ELISA method that was 0.6263 $\mathrm{ng} / \mathrm{mL}$. This result shows that the immunosensor method can be used as an alternative method for the determination of $\mathrm{ENaC}$ protein in a urine sample.

\section{Conclusions}

Anti-ENaC was successfully immobilized on the surface of reduced graphene oxide-modified screen-printed carbon electrodes by covalent bonds between - $\mathrm{COOH}$ groups of graphene oxide and $\mathrm{NH}_{2}$ terminals of anti-ENaC. The optimum concentration of anti-ENaC was $1 \mu \mathrm{g} / \mathrm{mL}$ for 30 min of incubation time and has revealed in a better response of the immunosensor. The immunosensor has the low-level detection of $\mathrm{ENaC}$ that can develop as a device for early detection of hypertension in urine samples.

\section{Acknowledgments}

This research supported by the PDUPT research scheme of the Indonesian Ministry of Research, Technology, and Higher Education No. No.2776/UN6.D/LT/2019. 


\section{Experimental}

\subsection{Materials and Methods}

Anti-ENaC antibodies and ENaC (Abcam), Graphene oxide (GO) (Sigma Aldrich), hydrochloric acid ( $\mathrm{HCl}$ ) (Merck; pa), bovine serum albumin (BSA) (Sigma Aldrich), carboxymethyl dextran (CMD) (Sigma Aldrich), 1-ethyl-3- (3-dimethyl aminopropyl) carbodiimide (EDC) (Sigma Aldrich), potassium ferricyanide $\left(\mathrm{K}_{3}\left[\mathrm{Fe}(\mathrm{CN})_{6}\right]\right.$ ) (Sigma Aldrich), graphene oxide (Graphenea SA ES A75022608), potassium hydrogen phosphate $\left(\mathrm{KH}_{2} \mathrm{PO}_{4}\right)$ (Merck; pa), potassium chloride $(\mathrm{KCl})$ (Merck), n-hydroxy succinimide (NHS) (Sigma Aldrich), sodium hydrogen phosphate $0.1 \mathrm{M}$ $\left(\mathrm{Na}_{2} \mathrm{HPO}_{4}\right)$ (Merck; pa), sodium hydroxide $(\mathrm{NaOH})$ (Merck; pa) sodium chloride (NaCl) (Merck; pa). Redistilled water (PT IKAPHARMNDO PUTRAMAS).

Zimmer and Peacock potentiostat connected to a computer using PSTrace 5.4 software is used for electrochemical measurements, SPCE (GSI Technologies, USA), modified and used as working electrodes, platinum electrodes $(\mathrm{Pt})$ as auxiliary electrode and $\mathrm{Ag} / \mathrm{AgCl}$ (saturated $\mathrm{KCl}$ ) electrode as comparative electrode, autoclave sterilizer (Prestige Medical SERIES 2100), FT-IR Spectrometer (Perkin Elmer Spectrum 100), balance sheet (Sartorius ENTRIS224-1S), micropipette (Eppendorf), Scanning Electron Microscope JSM-7500F (JEOL, USA), Centrifuge (Corning), Sonicator (Delta D68H, Taiwan), microtube (Eppendorf).

\subsection{General procedure}

\subsubsection{Reduction of Graphene Oxide (GO) and Modification of Electrodes}

Briefly, $1 \mathrm{mg} / \mathrm{mL}$ graphene oxide solution was sonicated for 15 minutes, then $40 \mu \mathrm{L}$ was dropped onto the surface of the SPCE electrode. Furthermore, GO reduction was carried out electrochemically using the cyclic voltammetric technique in the potential range of 0.1 to $-2.5 \mathrm{~V}$ with a scanning rate of $100 \mathrm{mV} / \mathrm{s}$ in 5 cycles. The electrode was then washed with PBS pH 7.4 and dried $30 \mathrm{~min}$ at room temperature.

\subsubsection{Immobilization of Anti-ENaC Antibodies on the Surface of the Electrode}

There were two immobilization techniques carried out in this experiment that were passive adsorption and covalent bonds formation. The first procedure carried out for passive adsorption was SPCE pretreatment. As much as $40 \mu \mathrm{L}$ PBS $1.0 \mathrm{mM} \mathrm{pH} 7.4$ was dropped onto SPCE-RGO, and potential of $-1.0 \mathrm{~V}$ was applied for 60 seconds. Then $20 \mu \mathrm{L}$ of anti-ENaC $0.1 \mu \mathrm{g} / \mathrm{mL}$ were dropped to the SPCE-RGO and incubated for $30 \mathrm{~min}$ at $4{ }^{\circ} \mathrm{C}$. The electrode was then rinsed with PBS solution $\mathrm{pH}$ 7.4. For covalent bond formation, modified SPCE-RGO was dropped with a $20 \mu \mathrm{L}$ of CMD solution containing $0.1 \mathrm{M} \mathrm{EDC}$ and $0.1 \mathrm{M}$ NHS with a ratio of $1: 1$ and incubated for 30 minutes at room temperature. Then the electrode was dropped with $20 \mu \mathrm{L}$ of anti-ENaC antibody $0.1 \mu \mathrm{g} / \mathrm{mL}$ and incubated for 30 minutes at room temperature. The electrode was then rinsed with PBS solution $\mathrm{pH}$ 7.4. Afterward, various anti-ENaC concentration were used to obtain the optimum experiment condition, that were $0.1 ; 0.5 ; 1 ; 2 ; 10 \mu \mathrm{g} / \mathrm{mL}$. Optimization of anti-ENaC incubation time also were done by incubating anti-ENaC for $0,30,60$, and 90 minutes.

\subsubsection{Determination of Immunosensor Response to ENaC}

The non-specific binding site of the electrode surface was blocked using a $0.5 \%$ BSA solution and incubated for 30 minutes at room temperature. Then the electrode was dropped with $20 \mu \mathrm{L}$ of $\mathrm{ENaC}$ and incubated for 1 hour at room temperature. The calibration curve was obtained by measuring 0 ; $0.09375 ; 0.1875 ; 0.375 ; 0.75 ; 1 ;$ and $1.5 \mathrm{ng} / \mathrm{mL}$ of ENaC. The immunosensor response was measured 
by differential pulse voltammetry with the potential range -1.0 to $1.0 \mathrm{~V}$, scanning rate at $0.008 \mathrm{~V} / \mathrm{s}$ using a redox system $10 \mathrm{mM} \mathrm{K}_{3}\left[\mathrm{Fe}(\mathrm{CN})_{6}\right]$ containing $\mathrm{KCl} 0.1 \mathrm{M}$.

\subsubsection{Optimization of Anti-ENaC Concentration and Incubation Time}

The SPCE-RGO electrode was incubated with $20 \mu \mathrm{L}$ of 1:1 (0.1 M EDC: $0.1 \mathrm{M}$ NHS) for 30 min at room temperature. Then the electrode was dropped with $20 \mu \mathrm{L}$ of the anti-ENaC $0.1 ; 0.5 ; 1 ; 2 ; 10$ $\mu \mathrm{g} / \mathrm{mL}$ respectively, and incubated for $30 \mathrm{~min}$ at room temperature. The electrode was then rinsed with PBS pH 7.4. To determine the optimum incubation time of anti-ENaC, the SPCE-RGO was dropped with $20 \mu \mathrm{L}$ of $1 \mu \mathrm{g} / \mathrm{mL}$ anti-ENaC and incubated for $10,30,60$, and 90 minutes respectively, at room temperature. The electrode was then rinsed with PBS pH 7.4.

\subsubsection{Analysis of Urine Samples}

Briefly, $20 \mathrm{~mL}$ of each urine sample was applied to the immunosensor, which proposed and incubated for 1 hour at room temperature. $\mathrm{ENaC}$ concentration was measured by differential pulse voltammetry in the potential range -1.0 to $1.0 \mathrm{~V}$ with a scanning rate of $0.008 \mathrm{~V} / \mathrm{s}$ using a redox system of $10 \mathrm{mM} \mathrm{K}_{3}\left[\mathrm{Fe}(\mathrm{CN})_{6}\right]$ containing $0.1 \mathrm{M} \mathrm{KCl}$.

\section{References}

1. Hosohata, K., Yoshioka, D., Tanaka, A., Ando, H., \& Fujimura, A. (2016). Early urinary biomarkers for renal tubular damage in spontaneously hypertensive rats on a high salt intake. Hypertens Res, 39(1), 19.

2. HERLITZ, H., DAHLÖF, B., JONSSON, O., \& FRIBERG, P. (1998). Relationship between salt and blood pressure in hypertensive patients on chronic ACE-inhibition. Blood pressure, $7(1), 47-52$.

3. Soundararajan, R., Pearce, D., Hughey, R. P., \& Kleyman, T. R. (2010). Role of epithelial sodium channels and their regulators in hypertension. J Biol Chem, 285(40), 30363-30369.

4. Su, Y. R., \& Menon, A. G. (2001). Epithelial sodium channels and hypertension. Drug metab dispos, 29(4), 553-556.

5. Hanukoglu, I., \& Hanukoglu, A. (2016). Epithelial sodium channel (ENaC) family: phylogeny, structure-function, tissue distribution, and associated inherited diseases. Gene, 579(2), 95-132.

6. Sofiatin, Y., \& Roesli, R. M. (2018). Detection of Urinary Epithelial Sodium Channel (ENaC) Protein. Am J Clin Med Res, 6(2), 20-23.

7. Rajesh, S., \& Singal, R. K. (2017). Single Frequency Impedance Analysis on Reduced Graphene Oxide Screen-Printed Electrode for Biomolecular Detection. Appl biochem biotech, 183(2), 672-683.

8. Tuteja, S. K., Ormsby, C., \& Neethirajan, S. (2018). Noninvasive label-free detection of cortisol and lactate using graphene embedded screen-printed electrode. Nano-micro lett, 10(3), 41.

9. Chan, K. F., Lim, H. N., Shams, N., Jayabal, S., Pandikumar, A., \& Huang, N. M. (2016). Fabrication of graphene/gold-modified screen-printed electrode for detection of carcinoembryonic antigen. Mater Sci Eng C, 58, 666-674.

10. Wahyuni, H. Y., Misonia, B. S. U., Santhy, W., \& Shabarni, G. (2018). A voltammetric immunosensor for detection of HER2 using gold modified-screen printed carbon electrode. Res J Chem Environ, 22(Special issue II), 294-301.

11. Hartati,Y.W., Nurdjanah, D., Wyantuti, S., Anggraeni, A., \& Gaffar, S. (2018). Gold nanoparticles modified screen-printed immunosensor for cancer biomarker HER2 determination based on anti HER2 bioconjugates, AIP Conference Proceedings 2049, 1, 020051.

12. Calvo, A. S., Botas, C., Martín-Yerga, D., Álvarez, P., Menéndez, R., \& Costa-García, A. (2015). Comparative study of screen-printed electrodes modified with graphene oxides reduced 
by a constant current. J Electrochem Soc, 162(10), B282-B290.

13. Teng, Y., Chen, T., Xu, F., Zhao, W., \& Liu, W. (2016). Screen-printed Carbon Electrode Modified with Commercial Multilayer Graphene for Lead Detection in Soybean Sauces by Differential Pulse Stripping Voltammetry. Int. J. Electrochem. Sci, 11, 1907-1917.

14. Jampasa, S., Siangproh, W., Duangmal, K., \& Chailapakul, O. (2016). Electrochemically reduced graphene oxide-modified screen-printed carbon electrodes for a simple and highly sensitive electrochemical detection of synthetic colorants in beverages. Talanta, 160, 113-124.

15. Xuan, X., Yoon, H. S., \& Park, J. Y. (2018). A wearable electrochemical glucose sensor based on simple and low-cost fabrication supported micro-patterned reduced graphene oxide nanocomposite electrode on flexible substrate. Biosens Bioelectron, 109, 75-82.

16. Kanyong, P., Rawlinson, S., \& Davis, J. (2016). A voltammetric sensor based on chemically reduced graphene oxide-modified screen-printed carbon electrode for the simultaneous analysis of uric acid, ascorbic acid and dopamine. Chemosensors, 4(4), 25.

17. Lu, Y., Huang, Y., Li, S., Zhang, Q., Wu, J., Xiong, Z., ... \& Liu, Q. (2017). Fat taste detection with odorant-binding proteins (OBPs) on screen-printed electrodes modified by reduced graphene oxide. Sensor acuat B-Chem, 252, 973-982.

18. Mehta, J., Vinayak, P., Tuteja, S. K., Chhabra, V. A., Bhardwaj, N., Paul, A. K., ... \& Deep, A. (2016). Graphene modified screen printed immunosensor for highly sensitive detection of parathion. Biosens Bioelectron, 83, 339-346.

19. Parkash, O., Yean, C., \& Shueb, R. (2014). Screen printed carbon electrode based electrochemical immunosensor for the detection of dengue NS1 antigen. Diagnostics, 4(4), 165180.

20. Miller, J.N., \& Miller, J.C. (2010) Statistics and chemometrics for analytical chemistry, 6th Ed. Pearson Education Limited, England.

21. Hartati, Y. W., Letelay, L. K., Gaffar, S., Wyantuti, S., \& Bahti, H. H. (2020). Cerium oxidemonoclonal antibody bioconjugate for electrochemical immunosensing of HER2 as a breast cancer biomarker. Sens Biosensing Res, 27. https://doi.org/10.1016/j.sbsr.2019.100316.

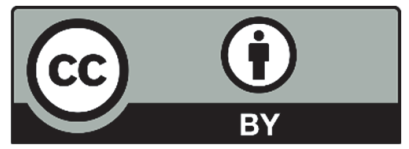

(C) 2020 by the authors; licensee Growing Science, Canada. This is an open access article distributed under the terms and conditions of the Creative Commons Attribution (CC-BY) license (http://creativecommons.org/licenses/by/4.0/). 